\title{
Um ciclo que se encerra e nossos melhores desejos para o que se inicia!
}

\section{An end of a cycle and our best wishes for the new beginning!}

\author{
Patricia Zeni Marchiori ${ }^{1}$, Andre Luiz Appel ${ }^{2}$, Eduardo Michelotti Bettoni ${ }^{2}$ \\ ${ }^{1}$ Universidade Federal do Paraná - UFPR, Curitiba, PR, Brasil \\ ${ }^{2}$ Grupo de Pesquisa UFPR/CNPq - Metodologias para Gestão da Informação, Curitiba, PR, Brasil
}

Autor para correspondência/Mail to: Patricia Zeni Marchiori (editoratoz@gmail.com)

\begin{abstract}
Copyright (C) 2017 Marchiori, Appel \& Bettoni. Todo o conteúdo da Revista (incluindo-se instruções, política editorial e modelos) está sob uma licença Creative Commons Atribuição-NãoComercial-Compartilhalgual 3.0 Não Adaptada. Ao serem publicados por esta Revista, os artigos são de livre uso em ambientes educacionais, de pesquisa e não comerciais, com atribuição de autoria obrigatória. Mais informações em http://revistas.ufpr.br/atoz/about/submissions\#copyrightNotice.
\end{abstract}

Entre várias simbologias, o número sete também remete à conclusão cíclica e à renovação. Este é o momento da AtoZ com o lançamento do v6n1 e, ato contínuo, a transição da gestão da Revista para uma nova equipe. Ao sexto ano de publicação soma-se um ano de intensos trabalhos do Grupo de Pesquisa em Metodologia em Gestão da Informação (UFPR/CNPq), em resposta à então Chefia do Departamento de Ciência, Gestão e Tecnologia da Informação (DECiGI), que solicitou ao Grupo a criação de um periódico científico-acadêmico na área.

Em 2010, o ano de ideação e desenho da Revista, parcerias foram estimuladas, pesquisadores contatados e sensibilizados, plataformas testadas, e foi encaminhada uma proposta de projeto de extensão à PROEC/UFPR, dando início ao posicionamento da AtoZ frente a suas duas missões:

a) ser um veículo de divulgação interdisciplinar, com foco em Gestão da Informação, voltado para jovens pesquisadores, e temáticas/metodologias inovadoras;

b) servir como um laboratório de pesquisas para a graduação e para a pós-graduação.

A Revista foi hospedada inicialmente em servidor próprio do DECiGI, onde o Grupo de Pesquisa pôde testar, aprovar (algumas) e descartar (muitas) das distintas possibilidades de gestão da plataforma OJS; de mecanismos para a chamada de trabalhos; de construção de parcerias, e de criação de políticas e normativas internas e diretrizes; assim como agregar outras ferramentas administrativas (e de informática) que vieram a auxiliar sobremaneira a gestão do Periódico.

O projeto de extensão (2011-2012) envolveu quatro alunos de graduação, sendo dois de Gestão da Informação e dois de Administração, tendo recebido premiação no respectivo Grupo de Trabalho na 4a.Semana Integrada de Ensino, Pesquisa e Extensão (SIEPE) da UFPR, de 2012. Em 2014 e 2015 a AtoZ submeteu - e teve aprovado dois projetos de Iniciação Científica (um para a criação de indicadores e outro para a elaboração de processos de diagramação baseados em LaTeX, igualmente premiados em seus respectivos Grupos de Trabalho da SIEPE); e estabeleceu uma parceria com a empresa Intelectus Ágil, para a discussão, aprimoramento e diagramação no formato epub. Em 2015, com o desenvolvimento de mecanismos internos para a geração semi-automatizada dos formatos pdf, html e epub - derivados da criação da Classe LaTeX AtoZ - esta parceria foi encerrada.

Também em 2015, a AtoZ passou a integrar o Portal de Periódicos da UFPR, migrando o conteúdo até então publicado, tendo atualizado algumas diretrizes e recebendo a atribuição DOI para todos os materiais. Uma vez na nova estrutura, a AtoZ também esteve habilitada a concorrer aos Editais de Apoio aos Periódicos do SIBI/UFPR, sendo contemplada em 2016. Os recursos deste Edital destinaram-se a dois bolsistas (um de graduação e um de nível técnico), ao se retomar a proposta da criação de indicadores para periódicos de acesso aberto. Neste particular, os resultados obtidos com o auxílio do Edital - que também permitiu completar a base BibTeX de todos os materiais da Revista - apontaram para aspectos de ajustes gerenciais (e operacionais), e oportunizaram novos estudos voltados à competitividade do Periódico.

A transferência da AtoZ para o Programa de Pós-Graduação em Ciência, Gestão e Tecnologia da Informação (PPGCGTI/UFPR) em 2016, e sua ascensão para o nível B2 na área de Comunicação e Informação (Qualis 20132016) são, igualmente, um coroamento do esforço da equipe editorial, dos seus colaboradores, apoiadores, autores; e do suporte oferecido pela Biblioteca Digital de Periódicos (BDP/SIBI/UFPR).

Neste v6n1 contamos com a entrevista cedida pela Mestre Daniela Spudeit e suas considerações sobre empreendedorismo e profissionais de informação; um short paper relatando a experiência de projeto de aprendizagem de informática com pessoas portadoras de deficiência intelectual, do professor da Universidade de Caxias do Sul/UCS, Paulo Antonio Pasqual Júnior; e dois artigos voltados para redes informacionais: o de Marcelo Silva e Rodolfo Azevedo, que apresentam e discutem o conceito de relações sociais de acesso, frente aos documentos policiais na Região do Alto Solimões/Amazonas; e a análise de interações em posts no Facebook de um candidato 
à Prefeitura de Maceió/AL, de autoria de Ronaldo Araújo, Sarah Santos e Janyelle Bento, da Universidade Federal de Alagoas.

Nos despedimos realizados, e com imensa gratidão àqueles que confiaram em nosso trabalho, que aceitaram convites para serem avaliadores permanentes ou ad hoc e, especialmente aos autores, que nos deram a honra de receber e encaminhar os resultados de suas pesquisa para a avaliação de um competente conselho científico, cuja finalização - em muitos casos - se consubstanciou na efetiva publicação do artigo, short paper ou entrevista. Aprendemos muito com todos e não há melhor retorno que este!

Convidamos a todos a darem continuidade à consolidação da AtoZ, e seguem aqui nossos mais fortes votos de sucesso ao novo grupo gestor, composto pelo Prof. Dr. Glauco Gomes de Menezes e pelas mestrandas Flávia Roberta Fernandes, e Cristiane Sinimbu Sanchez; todos do PPGCGTI/UFPR.

Abraço da equipe AtoZ!

Patricia Zeni Marchiori, Eduardo Michelotti Bettoni, Andre Luiz Appel \& Marcelo Batista de Carvalho. 